\title{
A Case of Intra-Uterine Amputation of the Right Humerus in the Lower Third.
}

\author{
By C. E. Dawson, L.R.C.P.
}

THE mother, aged 30 , had had one previous normal labour; that child, a female, being quite healthy and strong.

The second labour took place in January, 1903, prematurely at $6 \frac{1}{2}$ months as far as I could say. There was anto- and post-partum hæmorrhage but not alarming in quantity. The pains were normal. I was sent for on account of ante-partum hæmorrhage and pain. Upon examination per vaginam I felt something quite sharp, stretching across the vagina, which pricked my finger. Feeling it was part of an arm I very carefully pushed it up, and released the sharp end which had caught in the vaginal wall, and as the pains were strong and friquent the child, a female, was born without any further trouble. The placenta was expressed quite easily after which there was a ittle post-partum hæmorrhage, otherwise it was a perfectly normal labour.

Not a trace of the amputated limb could be found.

The patient made a good recovery. There were a slight rise of temperature and offensive lochia which soon cleared up after a few douchings with mercury biniodide $(1 \cdot 4000)$ by the woman in charge.

The child was ill-nourished at birth and cried feebly. It was wrapped in cotton-wool, after the usual bath, and took its food, milk and water from a bottle, indifferently, but gradually lost flesh and died from asthenia at the end of two weeks. The amputated limb looked exactly like the end of a sausage with the bone of the humerus protruding for $1 \frac{1}{2}$ inches; it was very sharp at the end and showed signs of absorption.

In the early period of this pregnancy the patient was whitewashing a ceiling when she suddenly felt acute pain in the abdomen which howe ver soon passed off, and thinking it was stomach-ache she thought nothing more of it. 